\title{
Direitos humanos e moral: os valores morais nas fases de positivação e de aplicação dos direitos humanos
}

\author{
Orlando Luiz Zanon Junior ${ }^{1}$
}

Resumo: O texto propõe um conceito axiológico de direitos humanos, no sentido de consubstanciarem-se interesses preponderantes de acordo com a moral compartilhada em determinado momento histórico. São também expostos critérios valorativos que permitem separar qualitativamente os direitos do homem das demais prerrogativas existentes. A corrente que defende os fundamentos éticos dos direitos humanos apresenta vantagens substanciais, diante de vertentes jusnaturalistas, historicistas e consensualistas, por reconhecer o fato irrefutável de que a justificativa dos direitos humanos é moral e, assim, reside nos valores compartilhados em dado momento histórico, bem como apresenta força de contenção em face de eventuais transgressões às prerrogativas essenciais, ao limitar a variabilidade (espacial e temporal) de seu conteúdo mínimo, através dos processos democráticos necessários à sua conformação na ordem positiva e à sua tutela jurisdicional. Por fim, o presente estudo sustenta a existência de uma relação de complementaridade entre direito e moral, perceptível nas fases de positivação e de aplicação.

Palavras-chave: Consensualista. Direitos humanos. Ética. Fundamentação. Historicista Jusnaturalista. Moral.
Abstract: The text proposes an axiological concept of human rights, as predominant interests, according to the morality shared in a specific historical moment. It also establishes four evaluative criteria to qualitatively separate human rights from other lesser rights. The studies that supports the ethical foundations of human rights has substantial advantages compared to the natural law, historicist and consensual studies, because it recognizes the irrefutable fact that the morality is the justification of the human rights and also because it restrains violations, by limiting the variability of the essential protection they confer, through the imposition of a democratic process to modify the law. Finally, this study supports the existence of a relationship of complementarity between law and morality, which is noticeable in the stages of legislation and enforcement.

Keywords: Consensual. Human rights. Ethical. Justification. Historicism. Natural Law. Morality.

1 Juiz de Direito. Pós-graduado em Preparação à Magistratura Federal pela Univali e em Direito e Gestão Judiciária pela UFSC. Mestrando em Direito pela UNESA. E-mail: olzanon@yahoo.com.br. 


\section{Introdução}

O texto apresenta uma proposta de fundamentação para os direitos humanos, com lastro no entendimento de que há uma relação de complementaridade entre a moral e o direito positivo, sem prejuízo das respectivas autonomias. Assim, na primeira seção do desenvolvimento, discorrese sobre o conceito de direitos humanos e apresentam-se critérios para aferição de quais prerrogativas jurídicas se enquadram em tal categoria.

Na segunda parte, é explicitada a importância da pesquisa filosófica acerca do fundamento dos direitos humanos, mormente em face de ordem jurídica com uma cláusula de abertura de conteúdo de prerrogativas essenciais, a exemplo da brasileira. Na sequência, são abordadas as principais correntes sobre o tema, consistentes nas propostas jusnaturalista, histórica, consensualista e ética. Após, justifica-se a opção por uma fundamentação de conteúdo moral.

E, na terceira e última seção, é explicitada a ideia de que o direito e a moral se articulam em uma relação que se revela pela manifestação de valores compartilhados socialmente, nas fases de positivação e de aplicação da norma, de acordo com os respectivos processos democráticos. Conclui-se, então, que os valores subjacentes ao direito, neste sentido, legitimam a norma e servem como critérios para a harmonização de interesses no caso concreto.

\section{Conceito de direitos humanos}

A discussão em torno dos direitos do homem inicia-se com um acordo semântico em torno das diversas expressões que os filósofos adotaram para designá-los, entre as quais, direitos da personalidade, direitos humanos, liberdades públicas, direitos públicos subjetivos, direitos fundamentais do homem, direitos naturais, direitos do cidadão e do trabalhador etc. A proliferação dessas diversas denominações decorre das suas diversas origens e da variação de fundamentos que lhe são atribuídos pelas diversas correntes de pensamento. Exemplificativamente, os norte-americanos preferem a expressão direitos civis (civil rights), 
em razão das diversas lutas que os colonos travaram para assegurar sua liberdade de cidadania perante o domínio externo e o próprio governo federativo; os alemães empregam a denominação direitos fundamentais, porque inseriram o rol das suas prerrogativas mais basilares na Lei Fundamental de seu Estado.

Para os fins deste estudo, adota-se a expressão direitos humanos para designar a categoria de prerrogativas essenciais da pessoa em sentido amplo, ainda que não positivadas em algum ordenamento jurídico, haja vista tratar-se da denominação mais difundida no cenário internacional, sendo inclusive a opção da Organização das Nações Unidas (ONU) na Declaração Universal dos Direitos Humanos de 1948. Por outro lado, reserva-se a designação direitos fundamentais para exprimir aquelas prerrogativas que foram reconhecidas politicamente e incorporadas à ordem jurídica de determinado Estado (CANOTILHO, 2003, p. 393), entendendo-se que é feita menção à legislação brasileira na falta de indicação de outro país.

Fixada a opção semântica, é possível afirmar que os direitos humanos são aqueles inerentes à personalidade humana, ou seja, incorporados à esfera jurídica do homem de forma a, efetivamente, torná-lo uma pessoa (ZANON, 2008, p. 37). Outrossim, trata-se das prerrogativas mais relevantes do ser humano, as quais devem ser respeitadas para assegurar o pleno desenvolvimento de sua dignidade (FERNANDEZ, 1991, p. 78).

Daí percebe-se uma dicotomia de cunho qualitativo, no sentido de que nem todos os rights são enquadráveis na categoria dos direitos humanos, mas tão somente aqueles essenciais à existência e evolução da espécie humana. A identificação de quais são os direitos humanos importa na discussão de seu conteúdo, cuja base reside na análise antropológica das necessidades humanas (FERNANDEZ, 1991, p. 79). Com efeito, somente a aferição das condições imprescindíveis para a existência e convivência harmônica dos homens permite abstrair quais as prerrogativas são fundamentais para o desenvolvimento da dignidade humana. Tal distinção é importante exatamente porque os direitos humanos, em face de seu caráter essencial, merecem uma proteção mais ampla, devendo prevalecer sobre interesses acessórios. 
Do próprio conceito de direitos humanos extraem-se parâmetros para sua identificação; porém esses apresentam caráter amplamente axiológico, exatamente porque se referem a proteções e faculdades com conteúdo valorativo no sentido de preservarem interesses admitidos politicamente, nos âmbitos internacional e interno de cada país (SARLET, 2008, p. 70). Assim, a ausência de critérios objetivos dificulta a classificação dos direitos dentro ou fora do rol dos direitos humanos. É possível, contudo, estabelecerem-se balizas mais estreitas para viabilizar o debate acerca da fixação do conteúdo e dos contornos dos direitos fundamentais, de modo a promover sua inserção nos ordenamentos jurídicos e posterior eficácia concreta.

Nessa trilha lógica, Luigi Ferrajoli (2006, p. 117-118) aponta três critérios axiológicos para delimitação do campo de abrangência dos direitos humanos de acordo com raciocínio de cunho metajurídico e metapolítico do constitucionalismo. O primeiro critério consiste na verificação da importância do direito para a promoção e manutenção da paz, consoante estabelecido no preâmbulo da Declaração de 1948. O segundo parâmetro é a relação entre o direito analisado com o postulado basilar da igualdade, no sentido de preservar as diferenças individuais, de tolerar o exercício lídimo da personalidade e de reduzir as iniquidades sociais. Por fim, o terceiro critério reside na característica do direito questionado visar à proteção da pessoa contra abordagens negativas e limitações de entidades mais fortes, como o Estado, as grandes corporações ou, simplesmente, alguém em situação de vantagem, ainda que momentânea.

Com lastro em Eusebio Fernandez (1991, p. 78), pode-se acrescentar como um quarto critério axiológico, a relação direta e imediata do direito com o princípio da dignidade da pessoa, no sentido de que somente devem ser consideradas essenciais as prerrogativas que sejam imprescindíveis para o pleno desenvolvimento da humanidade. Neste prisma de análise, os direitos humanos são "pretensões que, em cada momento histórico, descobrem-se a partir da perspectiva do valor da dignidade humana" (MENDES; COELHO; BRANCO, 2009, p. 271).

Importa ainda referir que direitos essenciais pressupõem deveres contrapostos de similar natureza, exigíveis perante o Estado ou outras pessoas, os quais lhe são complementares (FERNANDEZ, 1991, p. 79- 
80). Tal correlação entre prerrogativas e exigências não se apresenta somente na forma de abstenções, porquanto, além dos limites inerentes ao respeito e à tolerância, pode-se perceber a existência de direitos que demandam uma conduta proativa do outro para sua realização. Justamente por isto, a análise dos aspectos referentes aos direitos humanos não se foca isoladamente no titular dos rights, pois não se pode desconsiderar seus efeitos ante aqueles sobre os quais recaem as contraprestações respectivas. Ou seja, a escorreita compreensão de uma prerrogativa humanística não prescinde da apreciação do contexto onde se insere o seu titular, de modo a delimitar a sua extensão sobre os demais integrantes do grupo, perante os quais gera deveres correlatos. $\mathrm{O}$ preâmbulo do Pacto Internacional dos Direitos Civis e Políticos de 1966 expressa tal entendimento, ao levar em consideração o "fato de que o indivíduo tem deveres em relação a outrem e em relação à colectividade a que pertence e tem a responsabilidade de se esforçar a promover e respeitar os direitos reconhecidos no presente Pacto”.

A argumentação acima alinhavada referencia o substrato analítico básico para o diálogo democrático de afirmação do elenco de direitos humanos, cuja efetiva proteção depende da conjugação dos fatores políticos necessários para seu reconhecimento e inserção nos diversos ordenamentos jurídicos, como etapa preliminar e inafastável para sua concretização no cenário social.

No contexto brasileiro, o choque de forças emergentes do período de governo militar resultou na positivação de um amplo rol de direitos fundamentais, inserido no bojo da Constituição da República Federativa do Brasil de 1988 (CRFB/1988). Todavia, tal elenco expresso não é exaustivo, porque o $\S 2^{\circ}$ do art. $5^{\circ}$ da Carta Política brasileira amplia o quadro das prerrogativas essenciais para além daquelas constantes do seu Título II (art. $5^{\circ}$ a 17), ao prever que não estão excluídos outros direitos e garantias decorrentes do regime e dos princípios que adota, ou dos tratados internacionais em que a República Federativa do Brasil seja signatária. Notadamente, o referido preceito constitucional estabeleceu o "conceito materialmente aberto de direitos fundamentais no direito constitucional positivo brasileiro” (SARLET, 2008, p. 90-96). Daí a importância, também no âmbito jurídico brasileiro, de se estabelecerem parâmetros 
para o debate acerca de quais direitos, em razão de seu conteúdo, merecem ser incluídos na categoria dos fundamentais.

O Supremo Tribunal Federal (STF) já pode se manifestar sobre tal preceito constitucional no julgamento da Ação Direta de Inconstitucionalidade (ADI) $\mathrm{n}^{\circ} 939$ do Distrito Federal (DF), que versava sobre dispositivos da Emenda Constitucional (EC) $n^{\circ}$ 03/2003 e da Lei Complementar ${ }^{\circ}$ 77/1993. Naquela oportunidade, a Suprema Corte reconheceu que outros dispositivos da própria Lei Máxima, bem como preceitos constantes de diplomas infraconstitucionais ou tratados internacionais, podem contemplar direitos tidos como fundamentais pelo ordenamento jurídico brasileiro. Logo, forçosa a ilação de que também o STF adotou uma acepção material dos direitos fundamentais, superando uma abordagem meramente formal, na exata medida em que admitiu o status de fundamental para direitos não expressamente inscritos nos art. 5 a 17 da Constituição da República.

\section{Fundamentos dos direitos humanos}

A análise dos fundamentos dos direitos humanos é imprescindível para sua compreensão, porque viabiliza a descoberta do substrato teórico necessário para sua delimitação e aplicação concreta. Ressaltase, contudo, que os estudos acerca das razões justificadores dos direitos humanos não visam à descoberta de um fundamento absoluto, universal, único e incontestável, mas sim o reconhecimento das suas diversas bases justificadoras, como um fenômeno de origem multifatorial, imprescindível ao desenvolvimento humano.

Não se desconhece o argumento político de que a pesquisa filosófica acerca dos alicerces dos direitos humanos é irrelevante, calcado na ideia de que as declarações internacionais superaram tal discussão preliminar, transferindo o âmbito de diálogo para o campo da eficácia. Nesta linha de raciocínio, Norberto Bobbio (1992, p. 24) argumenta que "o problema fundamental, em relação aos direitos do homem, não é tanto o de justificá-los, mas o de protegê-los. Trata-se de um problema não filosófico, mas político”. Todavia, sem descurar da importância do 
debate sobre a efetividade das prerrogativas básicas do ser humano, não se pode concordar com os prosélitos da tese da desnecessidade de sua fundamentação teórica, por razões de ordem social, filosófica e técnicojurídica.

Com efeito, verifica-se que os direitos humanos são reiteradamente desrespeitados no cenário global, apesar do seu reconhecimento em vários ordenamentos jurídicos e em diversos documentos internacionais. Tal situação decorre, em parte, justamente pela "falta de fundamentos comuns que possam contribuir para universalizar o seu significado e, em consequência, a sua prática” (BARRETO, 2002). Outrossim, “a reflexão sobre os fundamentos dos direitos humanos somente tornou-se relevante e inseriu-se no plano de uma reflexão metajurídica, quando as violações destes direitos na prática cotidiana trouxeram consigo um alto grau de relativismo na sua interpretação” (BARRETO, 2002). Justamente por isso, a exposição dos elementos justificadores dos direitos humanos serve como condicionante de sua inserção nas diversas legislações e de baliza para sua posterior aplicação, de sorte a possibilitar sua concretização sem desprezo ou desconsideração dos fatores que ensejaram seu reconhecimento e sublimação no plano jurídico.

A apreciação dos motivos de existência dos direitos humanos também permite diagnosticar quais prerrogativas da humanidade merecem ser elevadas do rol das comuns para o patamar das fundamentais, cuja proteção jurídica geralmente apresenta força diferenciada, mediante inclusão em diplomas de hierarquia superior e prevalentes sobre os demais. Neste particular, a fundamentação dos direitos humanos é de especial interesse para os debates políticos sobre a necessidade de reconhecimento de determinado right, mediante processo democrático, para fins de sua posterior positivação, geralmente no bojo da Constituição do Estado. Sem embargo, a inserção de certa prerrogativa das pessoas na Carta Magna necessariamente perpassa por discussões políticas e jurídicas acerca da sua relevância e justificação como valor cujo conteúdo é preponderante para determinado grupo social. Como exemplo, remete-se às discussões parlamentares que ensejaram a elevação da "razoável duração do processo" como um direito fundamental, mediante sua inserção no art. 5, LXXVIII, da CRFB. 
Ainda nesse ponto, assevera-se que a adoção de cláusulas materialmente abertas de direitos humanos no bojo da Carta Política, a exemplo do já mencionado $\S 2^{\circ}$ do art. $5^{\circ}$ da CRFB, recomenda o debate filosófico acerca dos fundamentos dos direitos do homem, com o fim de viabilizar o reconhecimento judicial de prerrogativas essenciais ainda não expressamente inseridas no ordenamento constitucional. Trata-se de outra razão para se admitir que "não constitui tarefa meramente acadêmica e pode revelar-se importante para resolver problemas concretos. O esforço é necessário para identificar direitos fundamentais implícitos ou fora do catálogo expresso da Constituição” (MENDES; COELHO; BRANCO, 2009, p. 270). Daí extrai-se que só a ideia de fundamentalidade material pode fornecer suporte para "a abertura da constituição a outros direitos, também fundamentais, mas não constitucionalizados, isto é, direitos materialmente, mas não formalmente, fundamentais" (CANOTILHO, 2003, p. 379) e que apenas “uma compreensão aberta do âmbito normativo das normas concretamente consagradoras de direitos fundamentais possibilitará uma concretização e desenvolvimento plural de todo o sistema constitucional” (CANOTILHO, 2003, p. 379-380).

Além disso, a jurisdição constitucional pressupõe o exercício de ponderação dos valores fundantes dos direitos humanos em caso de contradição de normas, de modo a definir a sua realização concreta em caso de questionamento judicial. Instaurado um conflito envolvendo a aplicação de direitos humanos aparentemente contraditórios, a exata conformação jurisdicional da extensão de cada um certamente pressupõe a aferição judicial dos respectivos fundamentos, ou seja, das razões justificadoras de sua proteção jurídica. Muito embora a aplicação do direito esteja pautada pelas opções legislativas dos representantes democráticos, tal circunstância não ilide a valoração inerente à interpretação judicial, em razão da carga de pré-compreensão, ainda que com a suspensão das opiniões subjetivas particulares. Cabe salientar que, apesar do aprofundamento de tal tema ser mais adequado em sede de um estudo sobre hermenêutica jurídica, não se pode olvidar da relevância dos fundamentos dos direitos humanos como critério influente na sua aplicação judicial. 
Fixada a premissa acerca da importância quanto à fundamentação dos direitos humanos, importa analisar as principais formulações sobre o tema, representadas por quatro vertentes doutrinárias distintas, a saber: a) a jusnaturalista (direito natural); b) a historicista; c) a consensualista; e d) a ética ou axiológica.

A corrente jusnaturalista, mais tradicional e conhecida de todas, tem como pressupostos basilares a dicotomia entre os direitos natural e positivo e a supremacia do primeiro sobre o segundo. Conforme os prosélitos desta vertente, os direitos humanos são outorgados pela ordem jurídica natural, consubstanciando prerrogativas inerentes à personalidade que são superiores e anteriores à legislação, as quais apenas precisam ser reconhecidas e incorporadas ao ordenamento para fins sancionatórios. Nesta ótica, vislumbram-se as prerrogativas humanas como universais, invariáveis e válidas independentemente de sua inserção nos estatutos jurídicos particulares (FERNANDEZ, 1991, p. 93-94).

As críticas em face de tal linha de pensamento repousam na dificuldade de se estabelecer quais os direitos humanos com lastro apenas no argumento de pertinência à natureza humana, em face de sua imprecisão e ambiguidade, as quais implicam uma opção axiológica insuscetível de comprovação. Também a variação do rol dos direitos considerados essenciais ao longo do processo civilizatório contraria os argumentos de invariabilidade e de universalidade, na forma como aceita pelos jusnaturalistas. E, além disso, demonstrou-se historicamente equivocada a tese de que os direitos naturais são superiores e independem de prévia positivação, haja vista sua eficácia depender do reconhecimento pela ordem jurídica positiva.

A proposta historicista, por sua vez, consiste em admitir que os direitos humanos são variáveis em cada comunidade, modificando-se conforme o desenvolvimento societário ao longo das fases históricas, de acordo com o resultado das lutas políticas travadas no âmbito social. Os historicistas perceberam que "o elenco dos direitos do homem se modificou, e continua a se modificar, com a mudança das condições históricas, ou seja, dos carecimentos e dos interesses, das classes no poder, dos meios disponíveis para a realização dos mesmos, das 
transformações técnicas, etc.” (BOBBIO, 1992, p. 18). E, por isso, sustentam que as prerrogativas humanas "são construções culturais, relativamente homogêneas para determinados ambientes sociais” (ADEODATO, 2009, p. 127).

Critica-se esta abordagem porque, muito embora descreva com precisão a evolução dos direitos humanos ao longo da história, não apresenta o seu efetivo fundamento. Os historicistas não indicam as razões justificadoras dos direitos humanos, limitando-se a lhes atribuir uma característica inerente aos direitos em geral, consistente exatamente na mutabilidade histórica de suas conformações. Ora, “a história aponta a causa, a gênese ou origem de um fenômeno, e nunca seu fundamento" (BARZOTTO, 2006, p. 270). Acrescenta-se que a linha de pensamento em foco não percebe a existência de determinados rights reiteradamente reafirmados sem alterações no curso do progresso social, a exemplo dos direitos à vida e à integridade física (FERNANDEZ, 1991, p. 102). Ademais, apresenta-se contraditória à ideia de que certos direitos humanos possam ser considerados como essenciais e, simultaneamente, também totalmente variáveis ao longo do tempo ou do espaço, cabendo inclusive a sua supressão (BAEZ; BARRETO, 2007, p. 15).

A vertente consensualista defende que a sustentação dos direitos humanos é obtida por "meio do consenso geral acerca de sua validade” (BAEZ; BARRETO, 2007, p. 15). Para os seguidores deste posicionamento, a questão da fundamentação das prerrogativas da personalidade perdeu a importância, em razão da consagração das diretrizes mais amplamente aceitas na Declaração Universal de 1948.

A crítica a essa postura reside na constatação de que o consenso pode legitimar qualquer prática, a despeito de representar um retrocesso no desenvolvimento humano, porquanto viabiliza a reprodução de qualquer ideologia. Ademais, as considerações feitas acerca da tese historicista cabem aqui também, mormente à ausência de indicação precisa da justificativa dos direitos humanos.

Por derradeiro, a proposição ética ou axiológica parte dos pressupostos de que os fundamentos dos direitos humanos são extraídos dos valores prevalecentes da moral e de que sua eficácia depende 
do posterior reconhecimento de tais interesses predominantes pelo ordenamento positivo (FERNANDEZ, 1991, p. 106-107). Ou seja, os "homens têm direitos morais contra o Estado" (DWORKIN, 2007, p. 231), cuja efetividade depende de sua positivação e consequente tutela jurisdicional.

Essa tese difere substancialmente da linha jusnaturalista, não só por admitir a relevância do direito positivo como elemento imprescindível à conformação e eficácia dos direitos humanos, mas também por reconhecer a variabilidade histórica dos seus contornos, sem olvidar da projeção universal de seu núcleo essencial em determinada época. Nesta trilha lógica, os direitos humanos não são absolutos, atemporais e invariáveis, senão prerrogativas morais que podem ser justificadas racionalmente, com a pretensão de serem uniformes em determinado momento histórico (FERNANDEZ, 1991, p. 118).

A abordagem sob foco também não apresenta identidade com a corrente historicista, apesar de reconhecer a variabilidade da pauta axiológica predominante com o decurso do tempo, pois sustenta a necessidade de justificação ética e racional do conteúdo nuclear dos direitos do homem, de modo a permitir a universalização quanto ao seu delineamento e à sua eficácia, ao menos em dado lapso temporal. A proposta de fundamentação axiológica não olvida que o progresso social implica modificações nos contornos das necessidades humanas a serem juridicamente tuteladas, ao longo do tempo. No entanto, tais alterações atingem tão somente as matizes funcionais dos direitos do homem, porquanto a justificação moral obsta variações desconstitutivas do núcleo ético central das prerrogativas humanas já moralmente incorporadas. Assim, a carga jurídica elementar dos direitos humanos somente ampliase, embora sejam verificáveis modificações nos contornos funcionais dos direitos do homem, proporcionalmente às alterações decorrentes dos avanços sociais, tecnológicos ou políticos.

Das diferenças traçadas com relação às propostas anteriores de justificação, constata-se que a fundamentação ética admite o conteúdo axiológico subjacente à norma, o qual pode ser percebido tanto no seu nascimento (inserção no ordenamento jurídico), como no momento de 
sua aplicação concreta (interpretação judicial), mormente em se tratando das prerrogativas consideradas essenciais ao homem em determinada fase do caminhar civilizatório. Não se pode desconsiderar que o processo de positivação de determinado direito humano possui caráter nitidamente político, envolvendo a discussão democrática em torno dos valores que se pretende tutelar em cada contexto histórico. Da mesma forma, a proteção judicial de tais prerrogativas perpassa pela análise axiológica subjacente à norma, ainda que mediante suspensão dos preconceitos particulares. Notadamente, “o direito só pode ser compreendido no âmbito da atitude referida ao valor. O direito é uma manifestação cultural, isto é, um fato relacionado a um valor” (RADBRUCH, 2004, p. 11).

Importa assinalar que os valores incorporam-se ao direito através de complementação com a moral, que lhe serve de substrato axiológico, sem, contudo, galgar sobreposição. Por isso, afirma-se que "a ordem jurídica só pode ser legítima quando não contrariar princípios morais. Através dos componentes de legitimidade da validade jurídica, o direito adquire uma relação com a moral” e, bem assim, "a moral autônoma e o direito positivo, que depende de fundamentação, encontram-se numa relação de complementação recíproca” (HABERMAS, 2003, p. 141).

Os direitos humanos, entretanto, diferem dos demais porque seu conteúdo alberga valores morais mais elevados do que aqueles subjacentes às demais prerrogativas incorporadas ao ordenamento jurídico. Por isto, a identificação das prerrogativas essenciais compreende um cotejo qualitativo, que pode ser efetuado de acordo com quatro critérios axiológicos, conforme já exposto anteriormente: importância para fins de manutenção da paz, relação com o postulado da igualdade, finalidade de proteção dos hipossuficientes (FERRAJOLI, 2006, p. 117-118), e imprescindibilidade para o pleno desenvolvimento da dignidade humana (FERNANDEZ, 1991, p. 78).

A compreensão da dimensão ética como fundamento dos direitos humanos, consoante as balizas antes alinhavadas, ressalta o aspecto material do direito, no sentido de que conserva a promoção do justo e a repressão do injusto como seu conteúdo mínimo, a despeito das modificações históricas. Aliás, as discussões envolvendo a teoria da 
Constituição e os direitos humanos não sobrelevam a moral; ao contrário, “o aspecto material da constitucionalização tem apontado para um reforço entre os juristas de um conceito não positivista de Direito, no qual o sistema jurídico está vinculado à moral de forma conceitual, o que, aliás, pode ser um dos elementos que distinguem o constitucionalismo atual (neoconstitucionalismo) de suas versões precedentes” (STRECK, 2003, p. 101).

Ainda de acordo com as considerações acima delineadas, é possível extrair a ilação de que a fundamentação ética pressupõe um caráter dúplice, ético e jurídico dos direitos humanos. Ético no sentido de que a moral é relevante nas fases de positivação e de aplicação do direito. E jurídico porque a positivação é condição de eficácia dos valores subjacentes ao preceito normativo, cuja conformação é delineada pelos processos democráticos de criação e de aplicação do direito. Nesta perspectiva, o direito positivo representa os valores de justiça que são incorporados pelo legislador ao ordenamento jurídico para fins de promoção pelo gestor da coisa pública e de proteção pela jurisdição.

Poder-se-ia se criticar a consubstanciação da fundamentação ética dos direitos humanos na forma acima deduzida sob o argumento de que a admissão de uma moralidade relativa serve para embasar a discricionariedade política do legislador, a qual pode ensejar retrocessos no estágio civilizatório atual, na medida em que se reserva aos processos democráticos a liberdade de análise dos valores a serem tutelados juridicamente. Todavia, tal crítica não se sustenta, por cinco razões.

Primeiro, porque a eleição de critérios absolutos e invariáveis, de acordo com uma suposta racionalidade prática de cunho jusnaturalista, revela uma postura autoritária, de preferência por determinados argumentos em detrimento de outros que podem ser igualmente aceitos, engessando as vias democráticas no tocante à eleição das opções de condução da sociedade.

Segundo, porquanto a anulação da possibilidade de modificação da pauta axiológica subjacente ao direito, através da exclusão de determinados assuntos da possibilidade de conformação legislativa ou judicial, não pode ser justificada razoavelmente em um ambiente democrático. 
Terceiro, pois, mesmo numa abordagem espacial (variabilidade moral em diferentes culturas) é possível extrair uma pauta de valores básicos compartilhados globalmente, cujo grau de proteção vem historicamente sendo ampliado, ao menos no plano teórico. Com efeito, o multiculturalismo não impede o reconhecimento de uma moral mínima internacional, que representa os valores básicos informadores da justificação ética no âmbito global.

Quarto, porque, numa perspectiva histórica (variabilidade moral ao longo do tempo), é amplamente improvável uma alteração tão severa e abrupta no consenso moral global, ao ponto de admitir um retrocesso social que desconstitua ou derrua o núcleo básico próprio dos direitos humanos. Ora, nesta quadra da história, não se vislumbra viável, por exemplo, a possibilidade de justificação moral da tortura e da escravidão, exatamente porque já foram globalmente incorporados valores contrários a tais práticas, mormente considerando os parâmetros básicos já declarados no plano internacional. Ademais, ainda que tal involução pudesse ocorrer em tese, necessariamente não se estaria no contexto de uma democracia, a qual somente se concretiza com a viabilização de debates que não neguem os valores essenciais para a convivência harmônica, ainda que no tocante a direitos de minorias.

E, quinto, porquanto a positivação dos direitos humanos no ordenamento jurídico com status constitucional e a sua consequente proteção jurisdicional, mesmo contra maiorias eventuais do parlamento, ensejam a perpetuação dos valores éticos, ao menos em seu conteúdo principiológico basilar, a despeito de alterações de entendimentos políticos e morais compartilhados pela maior parte da população.

Nesse prisma de análise, a tese em foco apresenta vantagens substanciais diante das propostas jusnaturalista e historicista, porquanto reconhece o fato, irrefutável, de que o fundamento dos direitos humanos é moral e, assim, reside nos valores compartilhados em dado momento histórico, bem como, além disso, apresenta força de contenção em face de eventuais transgressões às prerrogativas essenciais, ao limitar a variabilidade (espacial e temporal) de seu conteúdo mínimo através dos processos democráticos necessários à sua conformação na ordem positiva e à sua tutela jurisdicional. 


\section{Valores morais nas fases de positivação e de aplicação nos direitos humanos}

O reconhecimento de uma valoração moral subjacente aos direitos humanos, consoante a teoria da fundamentação ética acima alinhavada, é irrefutável na fase de positivação e imprescindível ao equacionamento das tensões entre prerrogativas fundamentais. Nas linhas anteriores, foi esclarecido que os valores compartilhados socialmente influenciam o legislador, na fase de positivação dos direitos, e orientam o magistrado, no momento de resolução de controvérsias, no âmbito dos respectivos processos de afirmação democrática do direito. Resta para esta seção do desenvolvimento do texto, então, a explicitação destes dois momentos de manifestação dos valores subjacentes aos direitos humanos: as fases de positivação e de aplicação.

Inicialmente, quanto à fase de positivação, cabe assinalar que os valores emergentes dos embates políticos prévios configuram o substrato inicial para criação das normas, consubstanciando a razão de existência do ordenamento jurídico. Com efeito, a atividade criadora do direito é voltada para o fim de disciplinar a multiplicidade de ações e omissões possíveis no cenário social e econômico, com enfoque na proteção de determinados interesses e na promoção de certos valores. O elemento anímico do legislador é, então, condicionado pela moral compartilhada em determinado contexto histórico. Daí que a relação de complementaridade entre direito e moral é verificável desde o nascedouro do preceito normativo.

A inserção dos valores no ordenamento jurídico consubstancia um fenômeno complexo de choques políticos, sobre o qual duas peculiaridades merecem ser ressaltadas, mormente em se tratando de texto que versam sobre direitos humanos.

A primeira é a submissão do legislador aos valores mais elementares do Estado plasmados na Constituição. Isto porque, mesmo em se tratando de democracias representativas, a vontade majoritária, representada pelo parlamento, é dirigida pelos valores condutores eleitos pelo poder constituinte originário. Este efeito contramajoritário da Carta 
Política implica a vinculação dos poderes constituídos, inclusive dos representantes do povo, aos postulados que instituíram a sociedade.

Dessarte, os direitos humanos inseridos na Lei Fundamental encontram resguardo contra a força política das maiorias eventuais, que poderiam momentaneamente oporem sua força em face das prerrogativas de minorias. Tal contenção de potências majoritárias ocasionais revela a importância do direito, principalmente o constitucional, como instrumento mantenedor da moralidade mínima compartilhada. É exatamente aí que o direito apresenta seu aspecto conservador, o qual somente pode ser subtraído mediante uma conjugação de interesses políticos fortes o bastante, para, mediante um processo revolucionário (ainda que pacífico), promover a reforma ou a substituição da Constituição.

A segunda peculiaridade a ser abordada acerca do processo legiferante democrático reside na possibilidade de o legislador conformar o equilíbrio entre os valores fundamentais integrados na Constituição, desde que tal regulação não suprima o seu núcleo essencial. Assim, o processo legislativo representa a primeira instância de discussão sobre os direitos fundamentais, na qual são equilibrados os interesses contraditórios, mediante debates políticos calcados principalmente em argumentos axiológicos, observadas as balizas definidas pelo constituinte originário.

Sem embargo, “os valores últimos são antinômicos: não podem ser todos realizados globalmente e ao mesmo tempo. Para realizá-los, são necessárias concessões de ambas as partes: nessa obra de conciliação, que requer renúncias recíprocas, entram em jogo as preferências pessoais, as opções políticas, as orientações ideológicas” (BOBBIO, 1992, p. 18).

Do acima exposto, extrai-se que a instância preliminar para eficácia dos direitos humanos reside na atividade do legislador, a quem cabe efetuar o primeiro equacionamento axiológico de inserção dos valores morais no ordenamento jurídico, de sorte a conferir-lhes força cogente, mediante imposição do aparato estatal.

Todavia, a partir da positivação, o criador desvincula-se de sua obra. Ou seja, após as discussões políticas, as pretensões de tutela de determinados bens jurídicos cedem espaço para o texto prescritivo, o qual 
é desvinculado da vontade dos legisladores, adquirindo total autonomia. O dispositivo normativo como tal nada contém senão possibilidade de significação, embora tenha adquirido vigência e publicidade.

É posteriormente, na fase de aplicação, que se apreciam os planos de validade e de eficácia do texto legal, o qual se converte em norma mediante interpretação da mensagem que expressa, momento no qual os valores novamente exercem influência.

No que concerne a este segundo momento, em que se verifica a manifestação dos valores subjacentes ao direito, cabe assinalar que o aplicador, seja qual for (um particular contratando, um gestor público ou um juiz, por exemplo), condicionará moralmente a finalidade da norma, ainda que mediante a suspensão de seus preconceitos pessoais em favor dos princípios e regras que extrai do sistema normativo, de modo a harmonizar o direito à moral compartilhada no contexto histórico da interpretação.

Nessa linha de raciocínio, o intérprete percebe/concebe a norma do texto através de atividade intelectual que não pode ser compreendida afastada da moral que compartilha intersubjetivamente no contexto histórico. Isto porque, primeiro, o dispositivo normativo não é perceptível fora do cenário onde seu conteúdo deve se concretizar; e, segundo, o valor não é algo embutido em algum lugar secreto do preceito ou do diploma onde se insere, esperando para ser encontrado. Pelo contrário, o valor é compartilhado intersubjetivamente e condiciona a extração da norma como resposta à resolução do caso apresentado. Daí o papel da moral na fase de aplicação, como critério de harmonização da norma no momento de sua implementação fática.

Isso não significa, contudo, que o aplicador deva ler o texto através da lente de sua opinião pessoal, ou seja, com lastro naquele resultado que entende bom para o caso concreto, porquanto a moral não é o reflexo de seus interesses pessoais isoladamente. $\mathrm{O}$ valor subjacente à norma é, neste sentido, uma apreciação da moral compartilhada no âmbito onde deve incidir, a qual aflora mediante interpretação, razão pela qual pode, inclusive, variar conforme a evolução histórica do contexto interpretativo. 
O aprofundamento do tema atinente à fase de aplicação é matéria que foge ao escopo deste texto, dizendo respeito à interpretação do direito. A presente proposta visa a apenas demonstrar que a moral é critério de harmonização dos direitos humanos no caso concreto, motivo pelo qual duas considerações são pertinentes na espécie.

A primeira é que não se pode aceitar a moralização do direito, ou seja, a superação ou ultrapassagem de preceitos normativos além dos seus limites textuais com lastro em postulados axiológicos, sob pena de afronta ao processo democrático que previamente conformou o direito. Não se pode olvidar, neste particular, que "a interpretação acha-se vinculada a algo estabelecido. Por isso, os seus limites situam-se onde não existe algo estabelecido de forma vinculante pela Constituição, onde terminam as possibilidades de uma compreensão lógica do texto da norma, ou uma determinada solução está em clara contradição com esse texto” (HESSE, 2009, p. 116-117).

Exemplificativamente, se houver um preceito constitucional originário estabelecendo cotas para determinado grupo de pessoas em universidades públicas, o intérprete não pode deixar de aplicar a norma ao pretexto de ofensa ao dispositivo também fundamental que prevê a igualdade entre todos, porquanto tal interpretação nitidamente ultrapassa os limites previamente conformados pelo legislador constituinte.

E, segundo, importa assinalar que o controle da interpretação do direito, incluindo o aspecto valorativo, é efetuado mediante a prestação de contas consubstanciada na exposição de motivos, ou seja, na fundamentação. Ao estabelecer as razões de decidir, com publicidade geral, o intérprete enseja a universalização do decisum para novos casos que apresentem as mesmas características. Cria-se, desse modo, uma corrente de precedentes que somente pode ser quebrada mediante indicação de ausência de similaridade. Desta forma, a fundamentação tem o condão de obstar o chamado decisionismo, na medida em que impõe a indicação de uma condição suficiente como pressuposto para aplicação de uma decisão contrária a anterior.

Sobre o tema, Robert Alexy defende o sopesamento de valores (âmbito axiológico da norma) com o intuito de sustentar a ponderação de 
princípios (âmbito deontológico da norma, ou do dever-ser), afirmando que “a um tal modelo decisionista de sopesamento pode ser contraposto um modelo fundamentado. Em ambos os modelos o resultado do sopesamento é um enunciado de preferências condicionadas"; todavia, o modelo fundamentado "distingue entre o processo psíquico que conduz à definição do enunciado de preferência e sua fundamentação”, de modo a permitir a "fundamentação racional de enunciados que estabeleçam preferências condicionadas entre valores ou princípios colidentes” (2008, p. 165).

Nesse ponto, antevendo eventual crítica, importa consignar a ingenuidade de se compreender uma hermenêutica completamente despida de influências morais. Embora a superação da discricionariedade seja uma pretensão pós-positivista, sua base não se encontra na desvinculação entre direito e moral, conforme proposta na Teoria Pura do Direito (KELSEN, 2006, p. 167-178). Tampouco se compreende tal separação como necessária, principalmente em se tratando de direitos fundamentais, haja vista que "duas são as alternativas que se estabelecem no constitucionalismo contemporâneo (pós-guerra): ou os tribunais apenas garantem os direitos fixados no ordenamento-marco, sem qualquer capacidade de estabelecer posições jurídicas singulares, ou estão vinculados à eticidade substantiva da comunidade e, portanto, podem agir de forma a aproximar a norma da realidade. A evidência, é na segunda hipótese que se encontra a concepção de jurisdição compatível com os objetivos do Estado Democrático de Direito” (STRECK, 2003, p. 22).

Logo, pode-se concluir que há uma relação de complementaridade entre direito e moral, de modo que os direitos possuem um conteúdo ético perceptível nas fases de positivação e de aplicação. Quanto à legitimação dos direitos humanos, esta decorre do respeito ao processo democrático que, mediante debates políticos acerca dos valores a serem juridicamente tutelados, enseja a sua inserção no ordenamento jurídico. Na fase de aplicação, por outro lado, os direitos fundamentais são harmonizados no plano concreto, mediante a interpretação vinculada aos limites de conformação previamente traçados pelo legislador e controláveis pela fundamentação. Em se tratando de prerrogativas essenciais, a tensão entre direito e moral nos referidos momentos torna-se mais perceptível, em face da maior projeção de valores morais que encerram. 


\section{Conclusões}

Os direitos humanos são aqueles inerentes à personalidade humana, ou seja, incorporados à esfera jurídica do homem de forma à efetivamente torná-lo uma pessoa. Tal expressão designa a categoria de prerrogativas essenciais da pessoa em sentido amplo, ainda que não positivadas em algum ordenamento jurídico, haja vista que se trata da denominação mais difundida no cenário internacional, sendo inclusive a opção da ONU na Declaração Universal dos Direitos Humanos de 1948. A designação direitos fundamentais, por sua vez, exprime aqueles rights que foram reconhecidos politicamente e incorporados à ordem jurídica de determinado Estado.

Daí percebe-se uma dicotomia de cunho qualitativo, no sentido de que nem todos os rights são enquadráveis na categoria dos direitos humanos, mas tão somente aqueles essenciais à existência e evolução da espécie humana. Importa então estabelecer os quatro critérios axiológicos para a diferenciação das prerrogativas essenciais das demais, consistentes em: importância para fins de manutenção da paz; relação com o postulado da igualdade; finalidade de proteção dos hipossuficientes (FERRAJOLI, 2006, p. 117-118); e imprescindibilidade para o pleno desenvolvimento da dignidade humana (FERNANDEZ, 1991, p. 78).

Os direitos humanos pressupõem deveres contrapostos de similar natureza, exigíveis perante o Estado ou outras pessoas, os quais lhe são complementares sob a forma de abstenções e condutas proativas. Por isto, a análise dos aspectos referentes aos direitos humanos não se foca isoladamente no titular dos rights, pois não se pode desconsiderar seus efeitos ante aqueles sobre os quais recaem as contraprestações respectivas.

A análise dos fundamentos dos direitos humanos é imprescindível para sua compreensão porque viabiliza a descoberta do substrato teórico necessário para sua delimitação e aplicação concreta. Podem ser apontadas quatro justificativas para o estudo filosófico acerca dos direitos humanos: primeiro, a relevância da fundamentação como condicionante de sua inserção nas diversas legislações e como baliza para sua posterior 
aplicação; segundo, a imprescindibilidade da aferição dos motivos de existência dos direitos humanos também permite diagnosticar quais prerrogativas da humanidade merecem ser elevadas do rol das comuns para o patamar das fundamentais; terceiro, a adoção de cláusulas materialmente abertas de direitos humanos no bojo da Carta Política (a exemplo do $\S 2^{\circ}$ do art. $5^{\circ}$ da CRFB) recomenda a análise dos fundamentos dos direitos do homem, para o fim de viabilizar o reconhecimento judicial de prerrogativas essenciais ainda não expressamente inseridas no ordenamento constitucional; e, quarto, a jurisdição constitucional pressupõe o exercício de ponderação dos valores fundantes dos direitos humanos em caso de contradição de normas, de modo a definir a sua realização concreta em caso de questionamento judicial.

Existem quatro principais formulações sobre os fundamentos dos direitos do homem: a) a jusnaturalista (direito natural); b) a historicista; c) a consensualista; e d) a ética ou axiológica. A última proposta mencionada apresenta vantagens substanciais em relação às anteriores, porquanto reconhece o fato irrefutável de que o fundamento dos direitos humanos é moral e, assim, reside nos valores compartilhados em dado momento histórico; além disso, apresenta força de contenção em face de eventuais transgressões às prerrogativas essenciais, ao limitar a variabilidade (espacial e temporal) de seu conteúdo mínimo, através dos processos democráticos necessários à sua conformação na ordem positiva e à sua tutela jurisdicional.

O reconhecimento de uma valoração moral subjacente aos direitos humanos, consoante a teoria da fundamentação ética acima defendida, é irrefutável na fase de positivação e perceptível no momento de aplicação do direito.

Inicialmente, quanto à fase de positivação, cabe assinalar que os valores emergentes dos embates políticos prévios configuram o substrato inicial para a criação das normas, consubstanciando a razão de existência do ordenamento jurídico. O elemento anímico do legislador é, então, condicionado pela moral compartilhada em determinado contexto histórico. Daí a relação de complementaridade entre direito e moral ser verificável desde o nascedouro do preceito normativo. 
Todavia, a partir da positivação, o criador desvincula-se de sua obra. O dispositivo normativo como tal nada contém senão possibilidade de significação, embora tenha adquirido vigência e publicidade.

É posteriormente, na fase de aplicação, que se apreciam os planos de validade e de eficácia do texto legal, que se converte em norma mediante interpretação da mensagem que expressa, momento no qual novamente os valores têm influência. Com efeito, o intérprete condicionará moralmente a finalidade da norma, ainda que mediante suspensão de seus preconceitos pessoais em favor dos princípios e regras que extrai do sistema normativo, de modo a harmonizar o direito à moral compartilhada no contexto histórico da interpretação. O valor é compartilhado intersubjetivamente e condiciona a extração da norma como resposta à resolução do caso apresentado. Daí o papel da moral na fase de aplicação, como critério de harmonização da norma no momento de sua aplicação.

Portanto, pode-se concluir que há uma relação de complementaridade entre direito e moral, de modo que os direitos possuem um conteúdo ético, o qual é perceptível nas fases de positivação e de aplicação. Quanto à legitimação dos direitos humanos, esta decorre do respeito ao processo democrático que, mediante debates políticos acerca dos valores a serem juridicamente tutelados, enseja a sua inserção no ordenamento jurídico. Na fase de aplicação, por outro lado, os direitos humanos são harmonizados no plano concreto, mediante a interpretação vinculada aos limites de conformação previamente traçados pelo legislador e controláveis pela fundamentação. E, em se tratando de prerrogativas essenciais, a tensão entre direito e moral nos referidos momentos torna-se mais perceptível em face da maior projeção de valores morais que encerram.

\section{Referências}

ADEODATO, J. M. A retórica constitucional: sobre tolerância, direitos humanos e outros fundamentos éticos do direito positivo. São Paulo: Saraiva, 2009.

ALEXY, R. Teoria dos direitos fundamentais. São Paulo: Malheiros, 2008. 
BARRETO, V. P. Ética e direitos humanos: aporias preliminares. In: TORRES, R. L. (Org.). Legitimação dos direitos humanos. Rio de Janeiro: Renovar, 2002.

BARRETO, V. P.; BAEZ, N. L. X. Direitos humanos e globalização. In: BARRETO, V. P. BAEZ, N. L. X. (Org.). Direitos humanos em evolução. Joaçaba: Unoesc, 2007.

BARZOTTO, L. F. Os direitos humanos como direitos subjetivos: da dogmática jurídica à ética. In: SARLET, I. W. (Org.). Jurisdição e direitos fundamentais. v. 1. Porto Alegre: Livraria do Advogado, 2006, p. 239/280.

BOBBIO, N. A era dos direitos. Rio de Janeiro: Campus, 1992.

CANOTILHO, J. J. G. Direito constitucional e teoria da Constituição. 7. ed. Coimbra: Almedina, 2003.

DORNELAS, H. L. A questão da fundamentação dos direitos humanos. Disponível em: www.jusvi.com. Acesso em: 19 out. 2009.

DWORKIN, R. Levando os direitos a sério. 2. ed. São Paulo: Martins Fontes, 2007.

ECO, U. Como se faz uma tese. 21. ed. São Paulo: Perspectiva, 2007. FERNANDEZ, E. Teoria de la justicia y derechos humanos. Madri: Editorial Debate, 1991.

FERRAJOLI, L. Sobre los derechos fundamentales. Cuestiones constitucionales, n. 22, p. 113-136, 2006.

HABERMAS, J. Direito e democracia: entre facticidade e validade. v. 1. 2. ed. Rio de Janeiro: Tempo Brasileiro, 2003.

HESSE, K. A interpretação constitucional. In: HESSE, K. Temas fundamentais de direito constitucional. São Paulo: Saraiva, 2009.

KELSEN, H. Teoria pura do direito. 7. ed. São Paulo: Martins Fontes, 2006.

MENDES, G. F.; COELHO, I. M.; BRANCO, P. A. G. Curso de direito constitucional. 3. ed. São Paulo: Saraiva, 2009. 
MEZZAROBA, O.; MONTEIRO, C. S. Manual de metodologia da pesquisa no direito. 3. ed. São Paulo: Saraiva, 2007.

PASOLD, C. Prática da pesquisa jurídica. 9. ed. Florianópolis: Editora OAB/SC, 2005.

RADBRUCH, G. Filosofia do direito. São Paulo: Martins Fontes, 2004. STRECK, L. L. Jurisdição constitucional e hermenêutica. Rio de Janeiro: Forense, 2003.

ZANON JUNIOR, O. L. Direito constitucional. Florianópolis: Conceito, 2008.

Recebido em: 25/01/2010

Revisado em: 22/03/2010

Aprovado em: 02/04/2010 